REVIEW

\title{
A REVIEW- EFFECT OF SALT ON THE SENSORY PERCEPTION OF SNACKS
}

\author{
Ilze Kalnina*, Evita Straumite \\ Department of Food Technology, Faculty of Food Technology, Latvia University of Life Sciences and Technologies, \\ Rigas iela 22, Jelgava, Latvia, e-mail: kalnina_ilze@yahoo.com
}

\begin{abstract}
Consumers have growing concerns regarding healthy eating habits, which can lead to healthier food choices in both choosing meals and snacking. With the growing understanding of healthy foods, changing the motivation of food preferences towards healthier, producers are obligated to transform their products with a balanced nutrition value. One of greatest worries is the salt intake as it is connected to increasing risk of cardiovascular diseases. The challenge for producers is to decrease the amount of salt while at the same time maintain the good taste of snacks or any other products, in order to make sure that consumer liking remains at the same level. The objective of the review was to analyse scientific literature, describe the possibilities of salt reduction of potato, corn or vegetable snacks and to understand how it could impact sensory characteristics of the snacks. The review outlines the current situation of progress that has been made in salt reduction and indicates the main priorities and problems in the salty snacks sector. Salt as well as spices makes a great impact on sensory profile because they determine the taste of product, which is directly linked to overall level of liking. Researchers have found that it is possible to substitute salt with different salt replacers $\left(\mathrm{KCl}, \mathrm{MgCl}_{2}\right.$ and others) in combination with flavour enhancers. Salt reduction or replacing does not always directly affect consumer perception of products.
\end{abstract}

Keywords: salt reduction, snacks, sensory properties

\section{Introduction}

Salt is one of the most popular and most commonly used ingredients in the form of spices, additives and as well as food preservative in the food production sector. It ensures not only enhanced flavour and good texture but also contributes to extension of shelf-life (Mueller et al., 2016). Salt also can be used as an instrument to reduce taste of bitterness and decrease other off-tastes and enhance overall flavour intensity (Sinopoli, Lawless, 2012). However, salt is also one of causes that increase risks for high blood pressure, cardiovascular diseases and hypertension (He et al., 2013). The World Health Organization (WHO) recommends daily sodium intake for adults below $2 \mathrm{~g}$ ( $<5 \mathrm{~g}$ salt per day) (WHO, 2012b). The survey based on European Union (EU) salt reduction framework contains data collected from Member States from 1990s through 2012, where the main collection methods were: 24-hour dietary recall, collection of 24-hour urine samples and dietary records. The results showed that current daily salt consumption in Europe is estimated at 7-14 g per day, which is almost two times more than recommended daily intake (European Commission, 2013). These concerns regarding salt intake have led to the development of different strategies to reduce salt amount in food products - food reformulation by using salt replacers, salt mixtures, flavour enhancers (Desmond, 2006, Fellendorf et al., 2016); lowering salt amount gradually by stealth (Kilcast, Ridder, 2007; Liem et al., 2011); changing the size of salt (Desmond, 2006); changing the shape of salt, as well as different national initiatives like increasing awareness through public campaigns (Inguglia et al., 2017). As known, sodium's taste is primarily salty and sodium chloride is the saltiest sodium compound, whereas potassium and calcium has not only some component of saltiness, but they also have other flavours like "metallic" or "bitter" (Doyle, Glass, 2010). One of the most commonly used salt replacers is potassium chloride $(\mathrm{KCl})$ because of its salty characteristics. It has also been researched that increased potassium consumption may reduce the risk of cardiovascular disease and reduce blood pressure, while having a beneficial effect on bone-mineral density. Therefore, WHO recommends to increase potassium consumption from food for adults $(3.5 \mathrm{~g}$ potassium per day) in order to reduce risks of cardiovascular diseases (WHO, 2012a). The main food industry's concern regarding salt reduction in products is the impact on their sensory characteristics like texture and flavour, and overall acceptance of product.

Much of sodium intake comes from salt that is added to different snacks, such as chips, crackers, also dried and roasted nuts; in these cases, salt acts as flavour enhancer to snacks and it is consumed in particulate form as it isn't dissolved within the food (Chindapan et al., 2018). Potato chips and similar snacks from vegetables and wholegrains are very popular snack food which is consumed by various age groups between meals and during entertainment events. Therefore, it is also important to reduce salt in this food sector which could also partly contribute to global salt consumption reduction.

The aim of the review is to analyse scientific literature, describe the possibilities of salt reduction in potato, corn or vegetable snacks and to understand how it could impact sensory characteristics of the snacks. Review outlines the current situation of progress that has been made in salt reduction and indicates the main priorities and problems in the salty snacks sector. of the day (Wang et al., 2018). 


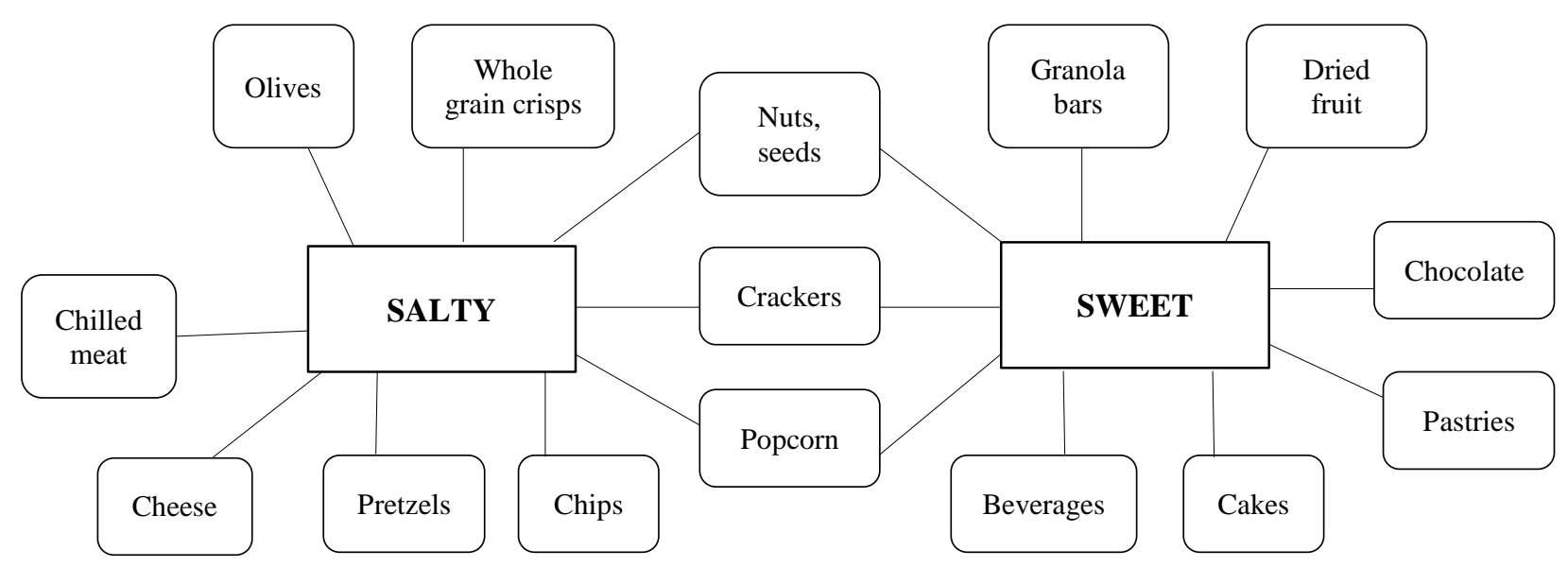

Figure 1. Examples of salty and sweet snacks

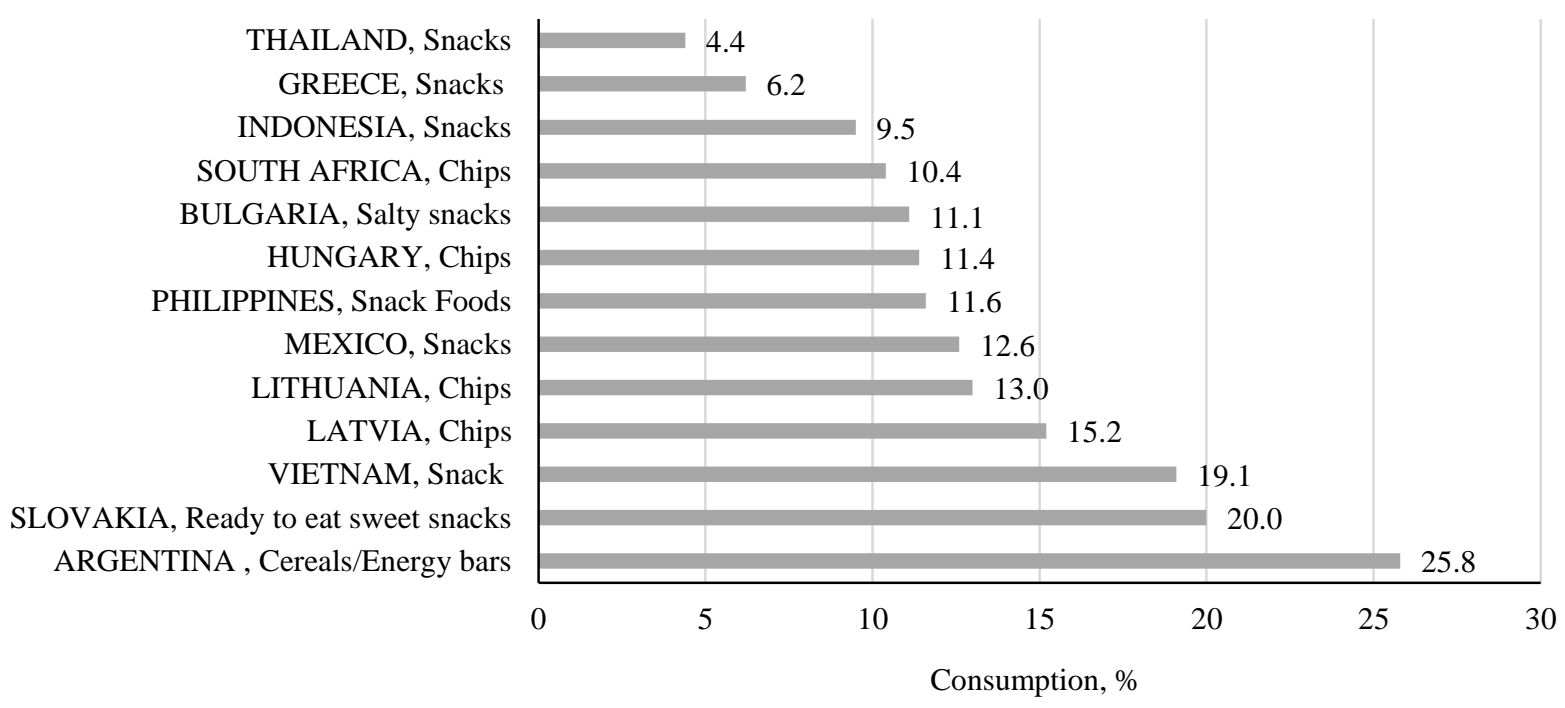

Figure 2. Countries where annual snack consumption is growing, \% (source: Nielsen Retail Measurement Service, 2014)

\section{Classification and consumption of snacks}

Snacking is eating in-between meals and it can be also described as any eating occasion outside of the main meals (breakfast, lunch or dinner).

The term "snacks" or "snack food" implies that these foods are energy dense and at the same time nutrientpoor, containing high amount of nutrients, consumption level of which should be limited, e.g., sugar, sodium, saturated fat; the most popular snacks are cookies, cakes, chips, nuts and other salty snacks as well as sweetened beverages (Hess, Slavin, 2018). The general classification of snacks from different scientific sources is summarised in Figure 1. Snacks can be divided in two groups - salty snacks and sweet snacks, where both categories include well-known products like chocolate and cookies as sweets and chips and pretzels as salty snacks. However, there are also products which can be included in either category depending and seasonings, e.g., nuts, crackers and popcorn. It is also important to remember that different consumers have different definitions for snacks (Hess, Slavin, 2018), it depends on society, friends, family, daily habits and eating motivations. Snacks usually are consumed daily between regular meals regardless of their healthiness and it is proved that access to free snacks and beverages at work is an important factor in employee satisfaction. Research by Baskin et al. (2016) showed that those employees who had access to free snacks at their workplace would report being very happy with their jobs by $20 \%$ more compared to those without available free snacks at work. It confirms once more that snacking is a part of daily routine, although snack consumption varies considering different eating motivations of each person. Snack choice is strongly linked to different geographical regions, the biggest sale contribution from overall snack category is confectionary, which includes sugary sweets like chocolate, candy, gum in Europe and Middle East/Asia (respectively $€ 41.2$ billion and $€ 1.7$ billion in 2014); salty snacks contribute more than one-fifth of snack sales in North America ( $€ 24.6$ billion in 2014), refrigerated snacks comprise almost one third of snacks in Asia-Pacific ( $€ 12.1$ billion in 2014) and cookies and snack cakes make up more than one-fourth of total snacks in Latin America ( $€ 7.6$ billion in 2014) (Nielsen retail measurement service, 2014). Nielsen Holding 
statistic data from year 2014 showed that there are growing sales of other snack categories like savoury snacks, which include crackers, rice cakes and pita chips, meat snacks, which include jerky and dried meat, refrigerated snacks, which include yogurt, cheese snacks and pudding.

Many emerging markets rise to the top of those with an increased appetite for snacks (Figure 2). Seeing sales growth in non-essential categories, like snacks, is a good indicator that consumers in these countries are ready and able to spend beyond the bare necessities, marking an incredible opportunity for fast-moving consumer goods companies in these markets (Nielsen retail measurement service, 2017).

\section{Salt consumption in Europe}

Europe Union (EU) strategy on nutrition, overweight and obesity related health issues sets out priorities to reduce ill health, where one of priorities is "making the healthier option available", which includes such initiatives as salt reduction campaigns (European Commission, 2013). In 2008 Member States agreed to create European Union Framework on voluntary national salt initiatives, where the overall aim on salt reduction was to contribute towards World Health Organisation (WHO) or national recommendations on salt intake level, and within the Salt Framework it was agreed to conduct a survey across the Member States collecting data from 2008 until 2012 (European Commission, 2013).

The salt intake among adults in most European countries ranges from 6.3 up to $13.6 \mathrm{~g}$ per day (Table 1). Table 1 shows mean values among adults both men and women. The lowest salt intake by survey data is in Germany, Cyprus, Bulgaria, Latvia and Sweden (6.3- 8.0 g per day), whereas the highest salt consumption was observed in Czech Republic, Slovenia, Hungary, Portugal and Poland (11.5-13.6 g per day).

Table 1

Estimated salt intake (g per day) of adults in EU (source: European Commission, 2013)

\begin{tabular}{lclc}
\hline Country & Adults & \multicolumn{1}{c}{ Country } & Adults \\
\hline Czech & 13.6 & Switzerland & 9.0 \\
Republic & & & \\
Slovenia & 12.7 & Netherlands & 8.8 \\
Hungary & 12.5 & Denmark & 8.6 \\
Portugal & 12.3 & France & 8.6 \\
Poland & 11.5 & Austria & 8.5 \\
Romania & 11.1 & Slovak & 8.2 \\
& & Republic & \\
Belgium & 10.5 & Finland & 8.1 \\
Estonia & 10.0 & United & 8.1 \\
& & Kingdom & \\
Norway & 10.0 & Sweden & 8.0 \\
Spain & 10.0 & Latvia & 7.3 \\
Ireland & 9.8 & Bulgaria & 7.1 \\
Italy & 9.6 & Cyprus & 6.5 \\
Luxembourg & 9.1 & Germany & 6.3 \\
Lithuania & 9.0 & & \\
\hline & & &
\end{tabular}

For now, there is not an international standard for labelling sodium versus salt; altering labels to display sodium may lead to consumer confusion because many do not understand difference between salt and sodium (Kloss et al., 2015). According EU Regulation No 1169/2011, the term salt instead of sodium must be used on food labels to ensure overall understanding. It is important to focus on ensuring consumer awareness of salt impact on health, especially because food recipe reformulation by the food industry is voluntary (Kloss et al., 2015).

\section{Strategies of salt reduction}

Current approaches in salt reduction are expressed in the following methods:

1. reducing salt amount in products gradually and at the same time changing society's awareness about healthy diet (Girgis et al., 2003; Liem et al., 2011);

2. salt reduction by partial replacement of sodium chloride (Liem et al., 2011; Paulsen et al., 2014; Fellendorf et al., 2016; Tamm et al., 2016);

3. additional application of flavour enhancers (Desmond, 2006; dos Santos et al., 2014) and use of aromas to enhance saltiness perception (Lawrence et al., 2011; Nasri et al., 2011);

4. changing physical characteristics of salt (Rama et al. 2013; Emorine et al., 2014).

However, it needs to be highlighted that salt reduction methods vary with different type of foods, it depends on various ingredients and also processing type used before consumption (Mitchell et al., 2011). In addition, different consumer age groups need to be taken into account because of their different sensory perceptions (Conroy et al., 2018).

\section{Salt replacers and flavour enhancers}

Salt enhancers do not have a salty taste themselves, but they enhance the salty taste when they are in combination with $\mathrm{NaCl}$; they activate receptors in the mouth and throat in order to help compensate the salt reduction (Rodrigues et al., 2016). Nevertheless, more detailed studies are required to explore this interaction. Different strategies have been developed for using salt replacers with many different substitutes and ingredient proportions to achieve the best result. The main purpose of substitution is to duplicate salt properties and maintain the same or better taste and other sensory features of product (Inguglia et al., 2017). Most commonly used salt replacers are made of mineral salts like potassium chloride $(\mathrm{KCl})$. Unfortunately, replacement of $\mathrm{NaCl}$ with $\mathrm{KCl}$ mostly has a negative impact on product flavour and texture, as well as colour. A research on fermented sausages showed that partial replacement of $\mathrm{NaCl}$ (above 40\%) with blend of $\mathrm{KCl}$ and glycine or K-lactate and glycine created negative effects of taste and texture (Gelabert et al., 2003). One of the main restrictions for using salt replacers is the additional flavour, which mostly is described as bitter and "metallic" caused by $\mathrm{KCl}$. Nevertheless, $\mathrm{KCl}$ is one of most widely used substitutes. In studies regarding salt reduction possibilities of potato chips, it was discovered 
that it is possible to partly substitute $\mathrm{NaCl}$ with $\mathrm{KCl}$, but it has significant effect on the acceptability of potato chips. Although reduced salt amount has a positive effect on purchase intent and in general partial $\mathrm{KCl}$ replacement maintains similar saltiness acceptability, but texture was significant aspect, which negatively affected overall product liking (Torrico et al., 2019). Magnesium sulphate also ensures salty taste similar to $\mathrm{KCl}$ but there is also a bitter aftertaste depending on the concentration.

Several studies on odour-induced saltiness enhancement (OISE) showed that it also is possible to reduce sodium content by using different aromas; although for the best result for sensory perception it would be better to combine this method together with other strategies, e.g., salt replacers and flavour enhancers, to maintain consumer acceptability (Nasri et al., 2011; Syarifuddin et al., 2016). OISE driving factors for solid food are odour quality and intensity, and in case of salt reduction, it is important to select aromas associated with saltiness like comté cheese and sardine odour, because odours, which are not associated with salty taste, e.g., carrot odour, do not enhance salt perception (Lawrence et al., 2011).

Flavour enhancers are another possibility, which can be used to reduce salt amount and improve product flavour. Some commonly used well-known flavour enhancers are yeast extracts, lactates, monosodium glutamate (MSG), nucleotides and hydrolysed vegetable protein (HVP) amongst others (Desmond, 2006). Studies have revealed that added MSG compounds that are responsible for a greater umami taste intensity enhance overall flavour intensity of potato chips (Zhang, Peterson, 2018). However, application of food enhancers also is limited - in case of MSG, it is classified as a food additive, which is generally not well appreciated by consumers; whereas in case of HVP and yeasts, they themselves have a salt content up to $40 \%$ and consequently the usage of them is limited. The study of Khetra et al. (2016) showed that it is possible to considerably reduce sodium amount in Cheddar cheese by using a combination of a salt replacer, HVP and adenosine-5'-monophosphate, which also in case of cheese reduced bitterness. Several studies found that one of best combinations for salt reduction is a mixture of $\mathrm{NaCl}, \mathrm{KCl}$ and MSG (Pereira et al., 2015; Rodrigues et al., 2016). The optimum salt content for chips and snacks in the snack sector has been observed at approximately $1.6 \% \mathrm{NaCl}$, research about salt level reduction in shoestring potatoes has shown that it is possible to maintain the same level of salt perception and similar sensory acceptability by using a mix of $\mathrm{NaCl}$ (30\%), MSG (30\%) and $\mathrm{KCl}(40 \%)$ to provide salt taste, where optimal formulation in product would be $0.48 \%$ of sodium chloride, $0.92 \%$ of potassium chloride, and $0.43 \%$ of monosodium glutamate, which accordingly would equivalent in salty taste to $1.6 \% \mathrm{NaCl}$ (Pereira et al., 2015). Several studies suggest that the amount of $\mathrm{KCl}$ as a partial salt replacer shouldn't exceed $40 \%$, as when it's above $40 \%$ sensory evaluation regarding flavour tends towards negative results due to pronounced bitterness and metallic taste (Gelabert et al., 2003; Pereira et al., 2015; Torrico et al., 2019).

\section{Change of salt size and shape}

Salt particle shape and size also has important function and it can be a convenient tool to attain desirable result in salt reduction. Alongside changing size of salt crystals, it is possible to change also the physical form of crystals - from granular to flakes. Flaked form has a higher solubility in the saliva due to the structure and, therefore, it is possible to use this in salt reduction strategy. It has also been proved, that flaked shape has a better water and fat binding characteristics than granular salt when used on red meat (Desmond, 2006). The biggest advantage is that flaked salt is a "clean" salt and there aren't additional flavours or changes in sensory perception while the drawback is its costs (Inguglia et al., 2017). Combination of particle size and form can achieve results with higher saltiness intensity as smaller size particles with wider surface area (flaked) and with highly agglomerated structure rapidly dissolves upon consumption (Rama et al., 2013; Quilaqueo et al., 2015). So, the salt structure also is important for salt perception - the smaller size of salt particles, the higher salt perception, because of faster release of the sodium molecule the maximum salt intensity is achieved sooner (Kloss et al., 2015).

Research on fried potato crisps coated with different sized salt particles showed that it has a considerable impact on the sodium delivery rate into saliva where smaller salt $(\mathrm{NaCl})$ crystals have quicker way to release sodium and thus, reach maximum perception of saltiness; it can be concluded that application of smaller or modified size salt crystals can be a way to reduce salt amount in potato chips (Rama et al., 2013). Studies about reducing the particle sizes combing with salt replacers $(\mathrm{KCl})$ and enhancers (MSG) in shoestring potatoes found that a smaller size not only intensified the taste of sodium chloride but also of monosodium glutamate, though the bitter and metallic taste, which are characteristics of potassium chloride at high concentrations, was not detected; in result the overall conclusion was that the combination of $\mathrm{NaCl}, \mathrm{KCl}$ and MSG with reduced particle size significantly promotes sodium reduction without a negative impact related to the sensory profile (Rodrigues et al., 2016).

Super small salt size can be obtained by mechanical grinding of larger salt crystals, anti-solvent crystallization or spray-drying, although particles gained from grinding or anti-solvent crystallization may display asymmetric morphology and a wide size distribution (Chindapan et al., 2018). Spray drying is a popular method, which is used to obtain micro and nano size particles with the possibility to control such properties as size, size distribution and morphology (Cho et al., 2015). From technological point of view, each of these methods are highly product dependent, for example, transforming salt crystal dissolution rate is beneficial for the dry product group (Busch et al., 2013). 
Moncada et al. (2015) concluded that cheese crackers which surface was treated with nano spray-dried salt particles (average size of particle $1.5 \mu \mathrm{m}$ ) had significantly higher saltiness scores than the crackers treated with regular salt (average size of particle $1500 \mu \mathrm{m})$. The results of Chindapan et al. (2018) study showed that spray-dried salt particles, in both combination with $\mathrm{KCl}$ and without it, had a significantly higher saltiness than commercial salt, these salts can be used to reduce sodium, especially in dry foods such as French fries, nuts, snacks etc. The research about salt reduction possibilities for pizza crust found that coarsegrained salt with crystal size $0.4-1.4 \mathrm{~mm}$ and aqueous salt solution led to a higher saltiness perception due to faster sodium availability, which allowed to reduce sodium amount up to $25 \%$ while keeping the same taste quality (Mueller et al., 2016). Spray-dried salt can be also used in combination with chitosan and acid microparticles, which ensures similar results with lower sodium amount but the same salinity perception (Yi et al., 2017).

\section{Sensory acceptability of snacks with reduced sodium content}

The main challenge for food manufacturers who are inclined to reformulate recipes in order to reduce salt amount is the level of sensory acceptability of product after changes. Overall, our society is also changing their food choice habits due to more healthier motivations, which is the result of different campaigns to spread the awareness of product quality, its ingredients and how these substances impact health. Thereby, food producers are forced to modify their products due to both society's awareness on health issues related to eating habits and market demands of food rich in nutrients. Torrico et al. (2019) revealed that sodium reduction by partially replacing it with $\mathrm{KCl}$ had a significant effect on the acceptability of potato chips, while the perception of saltiness remained at a similar level, but $\mathrm{KCl}$ also had an impact on texture which negatively affected overall liking, nevertheless, sodium reduction still made a positive effect on purchase intent.

\section{Conclusions}

The purpose of this review was to analyse scientific literature and summarize some of the possibilities to reduce salt amount in potato, corn or vegetable snacks and evaluate how it could impact sensory perception of the snacks. Different salt reduction strategies have a positive effect on snack overall acceptability by maintaining equal salt perception and improving purchase intent by indicating information about salt reduction on packaging. However, there is still a limited amount of studies regarding salt reduction possibilities in potato and vegetable chips, and wholegrain snacks. It is suggested that more studies in this area should be carried out.

\section{References}

1. Baskin E., Gorlin M., Chance Z., Novemsky N., Dhar R., Huskey K., Hatzis M. (2016) Proximity of snacks to beverages increases food consumption in the workplace: A field study. Appetite, Vol. 103, p. 244-248.

2. Busch J. L.H.C., Yong F. Y.S., Goh S. M. (2013) Sodium reduction: Optimizing product composition and structure towards increasing saltiness perception. Trends in Food Science and Technology, Vol. 29, p. 21-34.

3. Chindapan N., Niamnuy C., Devahastin S. (2018) Physical properties, morphology and saltiness of salt particles as affected by spray drying conditions and potassium chloride substitution. Powder Technology, Vol. 326, p. 265-271.

4. Cho H. Y., Kim B., Chun J. Y., Choi M. J. (2015) Effect of spray-drying process on physical properties of sodium chloride/maltodextrin complexes. Powder Technology, Vol. 277, p. 141-146.

5. Conroy P. M., O'Sullivan M. G., Hamill R. M., Kerry J. P. (2018) Impact on the physical and sensory properties of salt-and fat-reduced traditional Irish breakfast sausages on various age cohorts acceptance. Meat Science, Vol. 143, p. 190-198.

6. Desmond E. (2006) Reducing salt: A challenge for the meat industry. Meat Science, Vol. 74, p. 188-196.

7. dos Santos B. A., Campagnol P. C. B., Morgano M. A. Ô., Pollonio M. A. R. (2014) Monosodium glutamate, disodium inosinate, disodium guanylate, lysine and taurine improve the sensory quality of fermented cooked sausages with $50 \%$ and $75 \%$ replacement of $\mathrm{NaCl}$ with $\mathrm{KCl}$. Meat Science, Vol. 96, p. 509-513.

8. Doyle M. E., Glass K. A. (2010) Sodium reduction and its effect on food safety, food quality, and human health. Comprehensive Reviews in Food Science and Food Safety, Vol. 9, p. 44-56.

9. Emorine M., Septier C., Thomas-Danguin, T., Salles C. (2014) Ham particle size influences saltiness perception in flans. Journal of Food Science, Vol. 79 (4), p. 693-696.

10. European Commission (2013) Survey on Members States' Implementation of the EU Salt Reduction Framework. [accessed on 09.02.2019] Available: https://ec.europa.eu/health/sites/health/files/nutrition_phy sical_activity/docs/salt_report1_en.pdf

11. Fellendorf S., O'Sullivan M. G., Kerry J. P. (2016) Impact of ingredient replacers on the physicochemical properties and sensory quality of reduced salt and fat black puddings. Meat Science, Vol. 113, p. 17-25.

12. Gelabert J., Gou P., Guerrero L., Arnau J. (2003) Effect of sodium chloride replacement on some characteristics of fermented sausages. Meat Science, Vol. 65, p. 833-839.

13. Girgis S., Neal B., Prescott J., Prendergast J., Dumbrell S., Turner C., Woodward M. (2003) A one-quarter reduction in the salt content of bread can be made without detection. European Journal of Clinical Nutrition, Vol. 57, p. 616-620.

14. He F. J., Li J., Macgregor G. A. (2013) Effect of longerterm modest salt reduction on blood pressure. John Wiley \& Sons, $104 \mathrm{p}$.

15. Hess J. M., Slavin J. L. (2018) The benefits of defining "snacks". Physiology \& Behavior, Vol. 193, p. 284-287.

16. Inguglia E.S., Zhang Z., Tiwari B.K., Kerry P.J. (2017) Salt reduction strategies in processed meat products - A review. Trends in Food Science \& Technology, Vol. 59, p. 70-78.

17. Khetra Y., Kanawjia S.K., Puri R. (2016) Selection and optimization of salt replacer, flavour enhancer and bitter blocker for manufacturing low sodium Cheddar cheese 
using response surface methodology. LWT-Food Science and Technology, Vol. 72, p. 99-106.

18. Kilcast D., den Ridder C. (2007) Reducing salt in foods. practical strategies. Woodhead Publishing. p. 201-220.

19. Kloss L., Meyer J.D., Graeve L., Vetter W. (2015) Sodium intake and its reduction by food reformulation in the European Union - A review. NFS Journal, Vol. 1, p. 9-19.

20. Lawrence G., Salles C., Palicki O., Septier C., Busch J., Thomas-Danguin T. (2011) Using cross-modal interactions to counterbalance salt reduction in solid foods. International Dairy Journal, Vol. 21, p. 103-110.

21. Liem D. G., Miremadi F., Keast R.S.J. (2011) Reducing sodium in foods: The effect on flavour. Nutrients, Vol. 3, p. 694-711.

22. Mitchell M., Brunton N. P., Wilkinson M. G. (2011) Current salt reduction strategies and their effect on sensory acceptability: A study with reduced salt ready-meals. European Food Research and Technology, Vol. 232, p. $529-539$.

23. Moncada M., Astete C., Sabliov C., Olson D., Boeneke C., Aryana K. J. (2015) Nano spray-dried sodium chloride and its effects on the microbiological and sensory characteristics of surface-salted cheese crackers. Journal of Dairy Science, Vol. 98, p. 5946-5954.

24. Mueller E., Koehler P., Scherf K.A. (2016) Applicability of salt reduction strategies in pizza crust. Food Chemistry, Vol. 192, p. 1116-1123.

25. Nasri N., Beno N., Septier C., Salles C., ThomasDanguin T. (2011) Cross-modal interactions between taste and smell: Odour-induced saltiness enhancement depends on salt level. Food Quality and Preference, Vol. 22, p. 678-682.

26. Nielsen Company (2014) Snack Attack. What consumers are reaching for around the world? [accessed on 11.02.2019] Available: https://www.nielsen.com/content/ dam/nielsenglobal/kr/docs/global-report $/ 2014 /$ Nielsen\% 20Global\%20Snacking\%20Report\%20September\%2020 14.pdf

27. Nielsen Company (2017) Booming snack sales highlight a growth opportunity in emerging markets. [accessed in 11.02.2019] Available: https://www.nielsen.com/ma/en/ insights/news/2018/booming-snack-sales-highlight-agrowth-opportunity-in-emerging-markets.html

28. Paulsen M. T., Nys A., Kvarberg R., Hersleth M. (2014) Effects of $\mathrm{NaCl}$ substitution on the sensory properties of sausages: Temporal aspects. Meat Science, Vol. 98, p. $164-170$

29. Pereira H. C., de Souza V. R., Azevedo N. C., Rodrigues D. M., Nunes C. A., Pinheiro A. C. M. (2015)
Optimization of low sodium salts mix for shoestring potatoes. Journal of Food Science; Vol. 80, p. 1399-1403.

30. Quilaqueo M., Duizer L., Aguilera J. M. (2015) The morphology of salt crystals affects the perception of saltiness. Food Research International, Vol. 76, p. 675-681.

31. Rama R., Chiu N., Carvalho Da Silva M., Hewson L., Hort J., Fisk I. D. (2013) Impact of salt crystal size on in-mouth delivery of sodium and saltiness perception from snack foods. Journal of Texture Studies, Vol. 44, p. 338-345.

32. Rodrigues D. M., de Souza V. R., Mendes J. F., Nunes C. A., Pinheiro A.C.M. (2016) Microparticulated salts mix: An alternative to reducing sodium in shoestring potatoes. LWT - Food Science and Technology, Vol. 69, p. 390-399.

33. Sinopoli D.A., Lawless H. T. (2012) Taste properties of potassium chloride alone and in mixtures with sodium chloride using a Check-All-That-Apply method. Journal of Food Science, Vol. 77 (9), p. 319-322.

34. Syarifuddin A., Septier C., Salles C., Thomas-Danguin, T. (2016) Reducing salt and fat while maintaining taste: An approach on a model food system. Food Quality and Preference, Vol. 48, p. 59-69.

35. Tamm A., Bolumar T., Bajovic B., Toepfl S. (2016) Salt $(\mathrm{NaCl})$ reduction in cooked ham by a combined approach of high pressure treatment and the salt replacer $\mathrm{KCl}$. Innovative Food Science and Emerging Technologies, Vol. 36, p. 294-302.

36. Torrico D.D., Nguyen P.T., Li T,m Mena B., Viejo C.D., Fuentes S., Dunshea F.R. (2019) Sensory acceptability, quality and purchase intent of potato chips with reduced salt $(\mathrm{NaCl})$ concentrations. LWT-Food Science and Technology, Vol. 102, p. 347-355.

37. Wang D., Van Der Horst K., Jacquier E., Afeiche M., Eldridge A. (2018) Snacking patterns in children: A comparison between Australia, China, Mexico, and the US. Nutrients, Vol. 10, p. 1-13.

38. WHO (2012a) Guideline: Potassium intake for adults and children.

39. WHO (2012b) Guideline: Sodium intake for adults and children.

40. Yi C., Tsai M. L., Liu T. (2017) Spray-dried chitosan/acid/ $\mathrm{NaCl}$ microparticles enhance saltiness perception. Carbohydrate Polymers, Vol. 172, p. 246-256.

41. Zhang L., Peterson D. G. (2018) Identification of a novel umami compound in potatoes and potato chips. Food Chemistry, Vol. 240, p. 1219-1226. 